\title{
NEKATERE ZNAČILNOSTI MESTNE KLIME MARIBORA
}

\author{
Igor Žiberna *
}

IZVLEČEK

UDK 911.2:551.582(497.12-Maribor)

Prispevek obravnava razlike $\mathrm{v}$ vrednostih in trendih izbranih klimatskih parametrov med Mariborom in okolico.

ABSTRACT .

UDC 911.2:551.582(497.12-Maribor)

SOME CHARACTERISTICS OF THE MARIBOR URBAN CLIMATE

The article deals with the differences in values and trends of chosen climatic parameters between Maribor and its surroundings.

\section{UVOD}

Urbanizacija kot proces spreminjanja pokrajine je razen družbenogeografskih sprememb prinesla tudi spremembe $\mathbf{v}$ naravnem okolju mesta. Mesto s svojimi stavbami, asfaltnimi in betonskimi površinami in clovekovo dejavnostjo modificira tudi klimo.

Po Munnu (1966) je mehanizem nastajanja mestne klime naslednji:

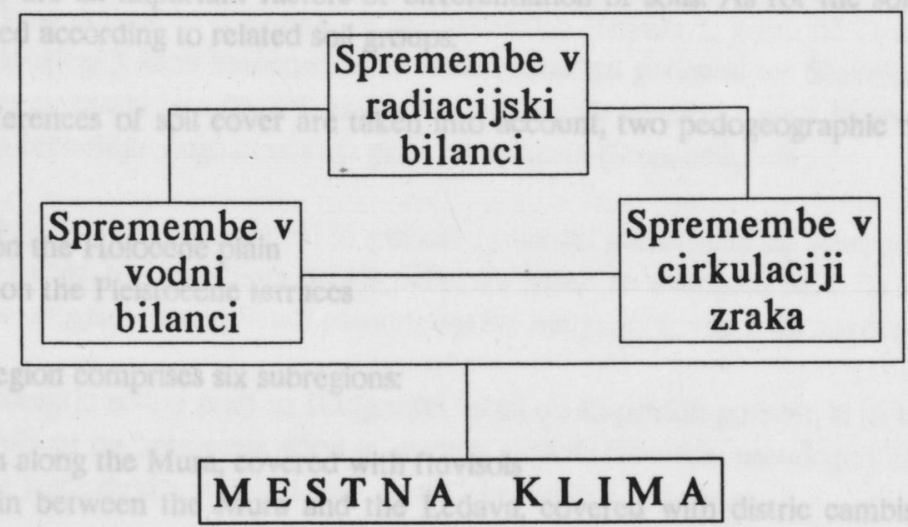

\footnotetext{
* Prof. geog, stažist raziskovalec, Oddelek za geografijo, Pedagołka fakulteta, Univerza v Mariboru, Koroðka cesta 160, 62000 Maribor, Slovenija.
} 


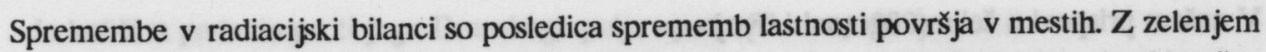
poraš̌ene površine so zamenjale asfaltne in betonske povrsine, ki imajo popolnoma drugačne termiðne lastnosti. Naslednji vzrok sprememb radiacijske bilance $\mathrm{v}$ mestih je clovekova aktivnost, ki naravnemu inputu energije dodaja še opazen lastni delež (Geiger, 1965; Arya, 1988). Rezultat se najpogosteje kaže $\mathrm{v}$ spremenjenih temperaturnih lastnostih mesta glede na okolico. Govorimo o t.i. "mestnem toplotnem otoku".

Tudi spremembe $\mathrm{v}$ vodni bilanci so posledica spremenjenih lastnosti povrsja $\mathrm{v}$ mestih. Zaradi hitrega odtekanja meteorne vode po kanalizacijskih ceveh in zaradi manj vegetacije $v$ mestih je tudi evapotranspiracija zmanjæana, kar se med drugim kaže $v$ manjłsi absolutni in relativni vlagi ter manjšem parnem pritisku v mestih (Landsberg, 1983).

Spremembe v cirkulaciji zraka pomenijo predvsem zmanjšnje hitrosti vetra zaradi upora, ki ga nudi hrapavo povrSje $v$ mestih. Po drugi strani pa mestni toplotni otok zlasti $v$ mirnem anticiklonalnem vremenskem tipu povzroča celǐ̌no kroženje zraka $\mathbf{v}$ prizemni plasti proti mestu, kjer se dviga in ponovno spuša izven mesta (Munn, 1966; Oke, 1978). Smer in hitrost vetra $v$ mestu pa lahko modificirajo tudi razne naravne ovire (gozd, relief, ipd.).

\section{PREDSTAVITEV METODOLOGIJE}

Obravnavanje mestne klime je lahko večplastno. Vidiki prourevanja mestne klime so sledeč:

- primerjava vrednosti klimatskih parametrov med mestom in okolico

- primer java trendov klimatskih parametrov med mestom in okolico

- primerjava vrednosti klimatskih parametrov v razlǐnih (tipicnih) delih mesta.

Za primerjavo vrednosti in trendov klimatskih parametrov med mestom in okolico je potrebno razpolagati $\mathrm{z}$ dolgoletnim nizom podatkov za meteorološko postajo $\mathrm{v}$ mestu in okolici, kar je zaradi redke mreže meteoroloskih postaj z ustrezno dolgim in neprekinjenim nizom opazovanj pogosto težko izvedljivo. Dodatna težava se pojavi tudi v primeru, ðe mikrolokacije meteoroloških postaj $\mathrm{v}$ mestu in $\mathrm{v}$ okolici niso dovolj reprezentativne za urbano oziroma ruralno pokrajino.

Še vexje težave se pojavljajo pri poskusu ugotavljanja klimatskih razlik znotraj mesta. Le redka mesta se namrex lahko pohvalijo $\mathrm{z}$ vec meteorološkimi postajami $\mathrm{z}$ dolgoletnim neprekinjenim nizom opazovanj. Mikrolokacija meteoroloških postaj pa igra tu še večji pomen.

Naslednja težava, na katero pri interpretaciji klimatoloških podatkov ne smemo pozabiti, je vpliv globalnih klimatskih sprememb, ki v dolgoletnih nizih dejansko oblikujejo trende klimatoloških parametrov (Šegota, 1988). Šele razlika v trendih (s tem izloximo vpliv globalnih klimatskih prememb) nam pove, ali mesto oblikuje specifǐne klimatske poteze. 
V našem prispevku želimo ugotoviti dvoje:

- s primerjavo izbranih klimatskih parametrov za meteorološki postaji v Mariboru in okolici želimo ugotoviti ali Maribor kot mesto ustvarja lastno (mestno) klimo.

- s primerjavo trendov izbranih klimatskih parametrov želimo ugotoviti razlike v spreminjanju klime v Mariboru in okolici.

Za oba postopka potrebujemo ustrezne pare meteoroloskih postaj v mestu in okolici. Kot primer mestne postaje smo bili prisiljeni izbrati meteorološko postajo Maribor-Tabor, ceprav njena lokacija za proucevanje mestne klime ni najprimernejša. Lokacija te meteoroloske postaje je bila prvotno na obmox̌ju današnje Elektrokovine, v zacetku šstdesetih let pa so jo preselili za nekaj sto metrov severozahodneje na današnjo lokacijo v bližini Tržaške ceste. Postaja je na robu obmox̌ja sklenjene zazidave. Južneje so le se posamezne stavbe servisne dejavnosti, od tu naprej pa se proti jugu siri Betnavski gozd in polja mariborskega Agrokombinata. Kot primer meteoroloske postaje izven mesta smo izbrali tisto na mariborskem letališcu. Podatki za to postajo obstajajo sele od leta 1977 naprej; problematična pa je tudi njena skrajno neprimerna mikrolokacija $\mathbf{v}$ bližini asfaltne letališke piste (meteoroloß̌ka hišica je od nje oddaljena le nekaj deset metrov).

Za ugotavljanje razlik $\mathrm{v}$ trendih je opazovalni niz letališke postaje prekratek. Zato smo kot komplementarno postajo izbrali tisto v Staršah, ki je kot temperaturna postaja začela delovati leta 1947. Popolnejsi podatki pa obstajajo sele od leta 1953 naprej (Povše, 1984).

\section{PRIMERJAVA IZBRANIH KLIMATSKII PARAMETROV MED MARIBOROM IN OKOLICO}

Primerjava srednjih letnih in srednjih sezonskih temperatur ob 7, 14. in 21. uri nam kaže, da so razlike med mestom in okolico največ je v hladni polovici dneva in pozimi (tabela 2). Leto smo razdelili na stiri sezone: zimo (december - februar), pomlad (marec - maj), poletje (junij avgust) in jesen (september - november). Razlike se కe jasneje kažejo v srednjih letnih ekstremnih, zlasti minimalnih temperaturah, ko je mesto kar za $1,2^{\circ} \mathrm{C}$ toplejse od okolice. Zanimivo pa je, da so razlike pri srednjih minimalnih temperaturah celo leto približno enake. Najve ${ }_{j}$ je temperaturne razlike nastopajo pri absolutnih ekstremnih temperaturah (pozimi kar za $5,2^{\circ} \mathrm{C}$ ). Tudi letno število dni $\mathrm{z}$ minimalno temperaturo pod $0,0^{\circ} \mathrm{C}$ je v Mariboru manjš za 82 dni (ali za $72 \%$ ) (tabela 1 in 2).

Relativna vlaga je v mestu nekaj manjæa, kar je za mestno klimo sicer normalen pojav. Razlike so najvecje pozimi in spomladi (med 4 in $5 \%$ ). Tudi povprečna oblačnost je v mestu nekaj večja, vendar so razlike zanemarljive. Število jasnih dni je v mestu nekaj manjše, stevilo oblačnih dni pa večje (spomladi kar za tretjino).

Večja količina padavin v Mariboru skoraj zagotovo ni posledica mestne klime pax pa dejstva, 
da kolixina padavin proti jugu Dravskega polja upada (Furlan, 1980).

Število dni $\mathrm{z}$ vetrom $\mathrm{s}$ hitrostjo nad 6 oziroma $8 \mathrm{Bf}$ je iz znanih razlogov (veð ja hrapavost povrకja) po priðakovanju manjše v mestu. Zanimivo pa je, da je število dni s kalmo (brezvetrjem) v mestu vse leto manjše. Razliko si lahko razložimo $\mathrm{z}$ različno lego obeh postaj. Medtem ko leži letališka postaja na ravnini, je mariborska na prehodu iz doline v ravnino in je kot taka bolj izpostavljena cirkulaciji zraka. Povprečna jakost vetra je v mestu za 0.3 Bf večja kot v okolici. To dokazuje tudi precej manjse stevilo dni $\mathrm{z}$ meglo jeseni in pozimi (tabela 2 ).

Maribor beleži letno za 44 dni manj megle kot letališce. Razlike nastopajo zaradi značaja površja $\mathbf{v}$ Mariboru in okolici, kajti vex vegetacije in $\mathbf{v}$ povprečju nižje temperature $\mathbf{v}$ mariborski okolici omogoxajo hitrejł̧i nastanek megle. Zelo pomembna je tudi večja prevetrenost v Mariboru.

Primer javo vrednosti klimatskih parametrov med mestom in okolico lahko sklenemo $\mathrm{z}$ ugotovitvijo, da se mestna klima kaže zlasti v temperaturnih razmerah. Toplotni otok v Mariboru je dinamixen pojav, ki se izraziteje pojavlja ponoxi in $v$ hladni polovici leta. Razlike $v$ relativni vlagi in oblačnosti so sorazmerno majhne, pri hitrostih vetra in stevilu dni z meglo pa relief zabrise ucinke mestne klime.

\section{PRIMERJAVA TRENDOV KLIMATSKIII PARAMETROV MED MESTOM IN OKOLICO}

Pri izracunu trendov izbranih klimatskih parametrov smo uporabili podatke metcoroloških postaj Maribor-Tabor in Starše. Slednja ima namreč daljši opazovalni niz od tistega na letališcu. Trende smo izracunali za obdobje 1953 - 1990. Pred letom 1953 so podatki za Starše pogosto nepopolni. Pri relativni vlagi smo zaradi istega razloga obdelali trende le za obdobje 1970 1990. Trende smo račnali za leto in posamezne sezone, $s$ cimer smo želeli ugotoviti, ali imajo razlike med mestom in okolico sezonski zna×aj.

Primerjava trendov dobljenih na osnovi srednjih sezonskih temperatur kaže, da se mesto v splošnem bolj segreva od okolice. Največje razlike nastopajo pozimi (mesto se je $\mathrm{v}$ omenjenem obdobju $v$ zimskih mesecih v primerjavi $z$ okolico segrelo za skoraj $0,3^{\circ} \mathrm{C}$ na deset let), najmanjše pa spomladi oziroma poleti (tabela 3 ). Tudi pri razlikah trendov maksimalnih in minimalnih temperatur nastopajo najvecje razlike pozimi in najmanjše poleti (pri obeh so zime $v$ mestu vsakih deset let toplejse od okolice v povprecju za $0,2^{\circ} \mathrm{C}$ ) (tabela 3 ). Glede na to, da so razlike $\mathrm{v}$ temperaturnih trendih najvexje pozimi lahko sklepamo, da $\mathrm{k}$ nastanku toplotnega otoka opazno vpliva po cloveku povzročen input energije zaradi kurilne sczone.

Trendi relativne vlage, količine oblačnosti in števila dni z meglo kažejo rezultate, ki so v nasprotju $\mathrm{s}$ pricakovanimi. Tako se relativna vlaga $\mathrm{v}$ mestu $\mathrm{v}$ primerjavi $\mathrm{s}$ tisto $\mathrm{v}$ okolici celo 
povečuje. Srednja oblačnost in letno stevilo dni z meglo se v mestu zmanjふ̌ujeta, v Starక̌a pa povecujeta. Posledica naštetega je pozitivni trend insolacije v Mariboru! (tabela 3). Upoštevati pa moramo, da lege postaj zaradi okoliskega reliefa niso povsem primerljive. Veðja prevetrenost v Mariboru gotovo pomembno vpliva na zmanjక̌anje Stevila dni z meglo. Svoje prispeva tudi fenizacija vetrov na vzhodnem obrobju Pohorja (Gams, 1972).

Trendi in razlike $\mathrm{v}$ trendih med mestom in okolico torej kažejo na oblikovanje toplotnega otoka, ki je izrazitejsi v hladni polovici leta.

\section{ZAKLJUČEK}

Razlike med Mariborom in okolico se kažejo zlasti v temperaturnih razmerah. Pozimi oziroma ponoxi se $\mathrm{v}$ mestu oblikuje toplotni otok. Temperaturne razlike med mestom in okolico znasajo pozimi v povprexju $0,7^{\circ} \mathrm{C}$, poleti pa so nekaj manjß̌e. Š vecje razlike se pojavljajo pri srednjih in absolutnih ekstremnih temperaturah. Obstoj mestnega toplotnega otoka dokazujejo tudi razlike $\mathbf{v}$ trendih srednjih in srednjih ekstremnih temperatur. Glede na to, da so razlike najvec je $\mathrm{v}$ hladni polovici leta in dneva lahko sklepamo, da pri nastajanju toplotnga otoka igra pomembno vlogo po cloveku povzroceni input energije zaradi kurilne sezone.

Nekateri drugi klimatski parametri kot so relativna vlaga, hitrost vetra, oblačnost in število dni $\mathrm{z}$ meglo ne kažejo vrednosti, ki bi bile znacilne za mestno klimo. Nanje očitno vpliva drugačna lega mesta oziroma relief.

\section{LITERATURA IN VIRI}

Arhiv HMZ RS

Arya S.P., 1988, Introduction to Micrometeorology, Academic Press inc., San Diego

Furlan D., 1980, Klimatski prikaz Severovzhodne Slovenije s posebnim poudarkom na padavinah, HMZ, Ljubljana

Gams I., 1972, Vprašanje klimatogeografske rajonizacije Severovzhodne Slovenije, Geographica Slovenica, II, Maribor

Geiger R., 1965, The Climate near the Ground, Harvard University Press, Cambridge Landsberg H.E., 1983, Klimat goroda, Gidrometeoizdat, Leningrad

Munn R.E., 1966, Descriptive Micrometeorology, Academic Press, New York and London Oke T.R., 1978, Boundary Layer Climates, Methuen and Co., London Šegota T,, 1988, Klimatologija za geografe, Školska knjiga, Zagreb 


\section{SOME CHARACTERISTICS OF THE MARIBOR URBAN CLIMATE}

Urbanisation as a process of changing landscape has brought beside social geographical changes also changes in natural landscape of the town as well. The town with its buildings, asphalt and concrete areas and human activities is modifying the climate, too. Formation of city climate according Munn (1966) in mutual effection causes the changes in radiation and water balance and in the circulation of the air.

Discussing the city climate can be multilayered. We can find out the differences in climate parameters and trends of climate parameters between urban and rural areas. On the other hand we can also compare the condition of climatic parameters in different (typical) parts of the town.

In our contribution we wish to state the following:

1. Comparing climatic parameters for meteorologic stations in Maribor and surroundings we wanted to determine, if Maribor as a city creates its own (city) climate.

2. Comparing trends of certain climatic parameters we wanted to determine the differences of changing the climate in Maribor and its sorroundings.

The results show, that the differences between Maribor and its surroundings are present in temperature conditions. In winter as well as at night in the city a heat island is formed. The differences in temperature between the city and its surroundings are in winter on the average $0,7^{\circ} \mathrm{C}$; in the summer they are a little lower. Higher differences appear by mean extreme temperatures and absolute extreme temperatures. The existence of the city heat island demonstrates the differences in average trends as well as in mean extreme temperatures. According that the highest differences are in the colder part of the year and day, we can conclude that a major factor in forming the city heat island is man with the input of the energy in the heat supplying season.

Other climatic parameters as relative humidity, wind speed, cloudiness and number of days with fog do not demonstrate the values, which would be typical for the city climate. It is evident, that they are affected by the different city site and relief respectively. 

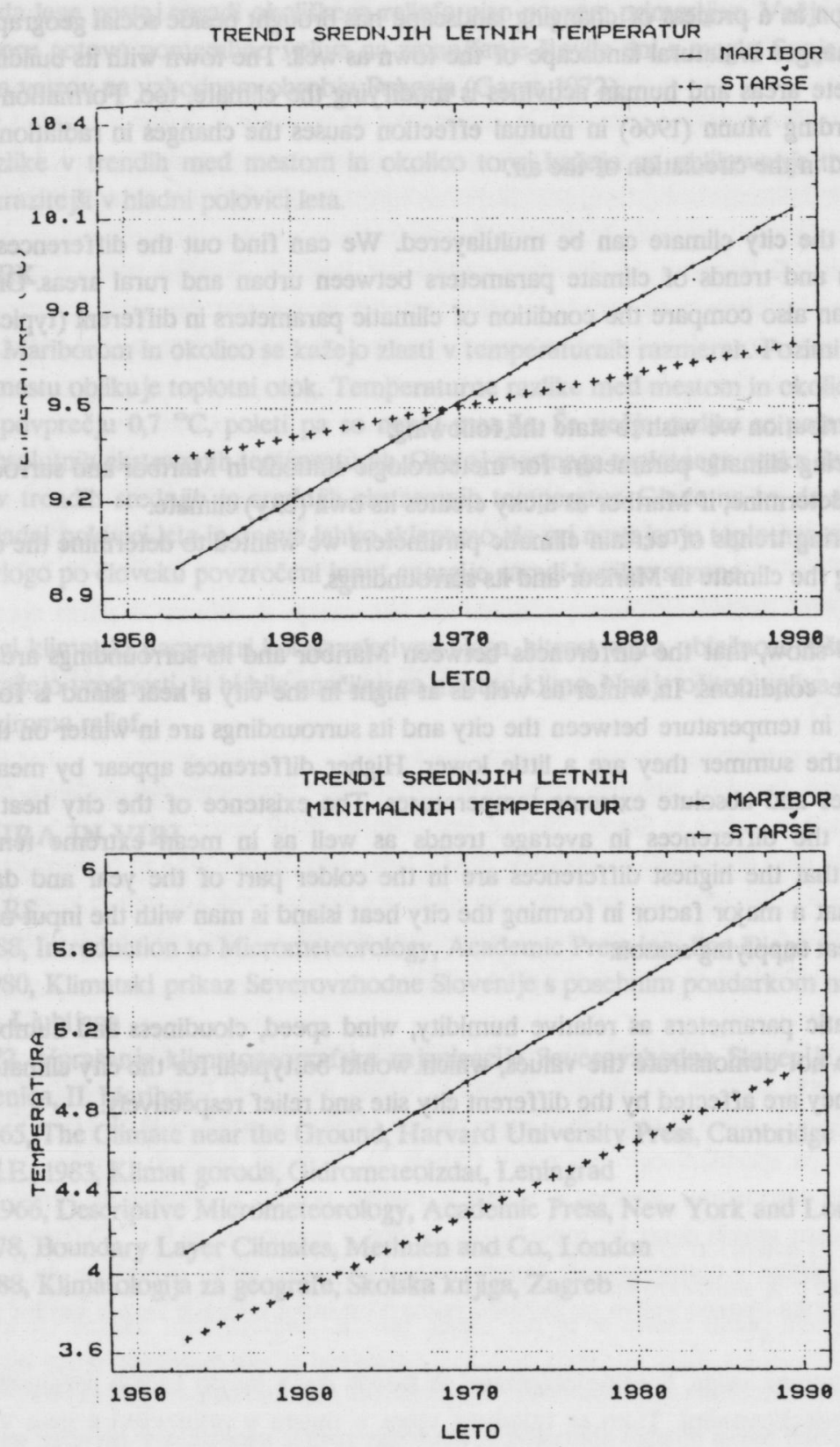

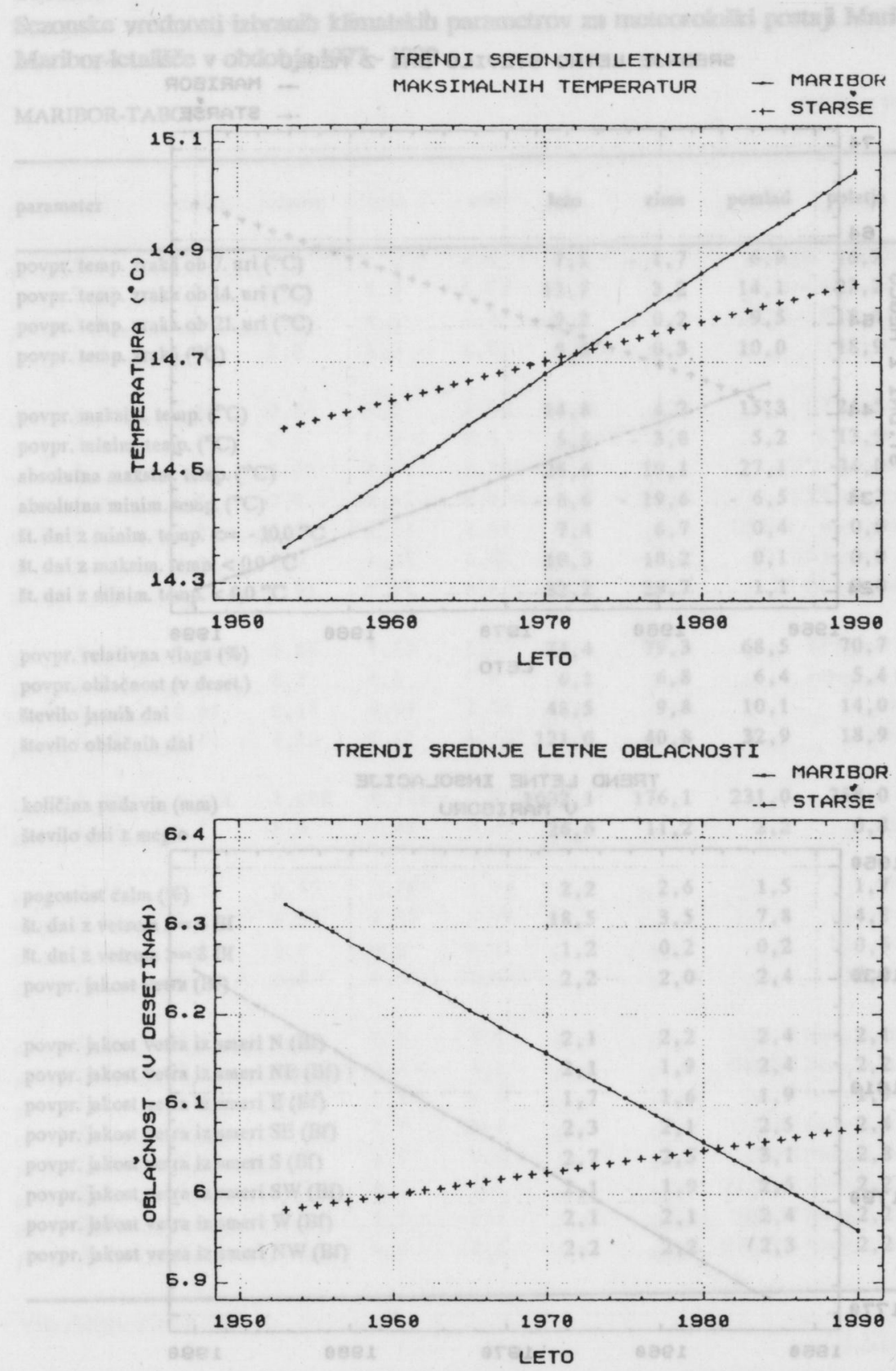
SREDNJE LETNO STEUILO DNI $Z$ MEQLO

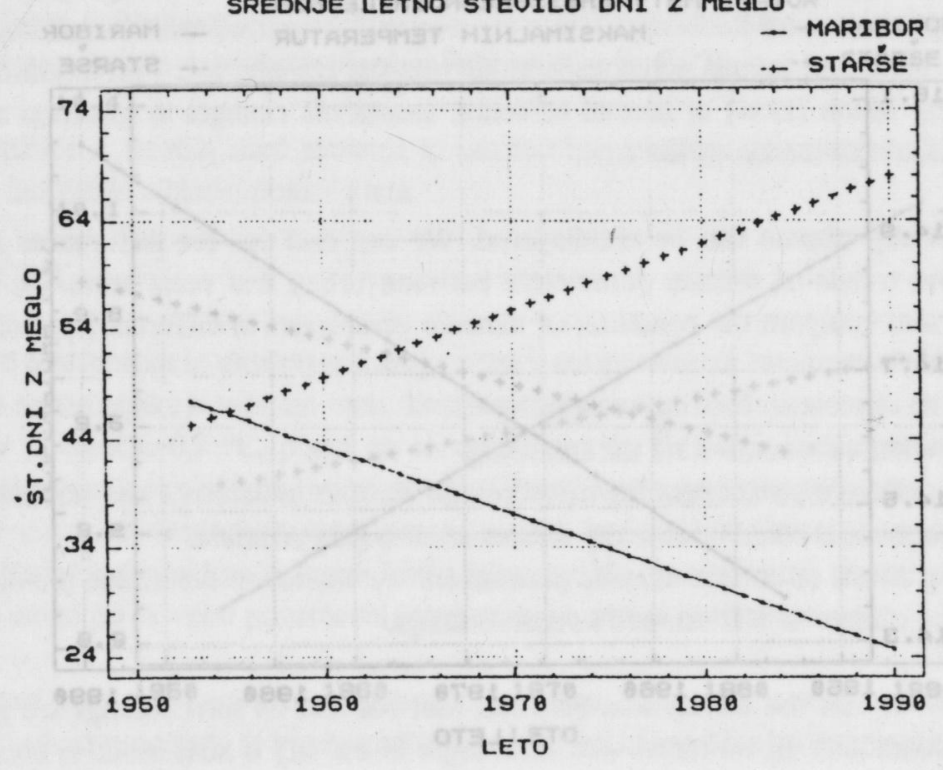

TREND LETNE INSOLACIJE U MARIBORU

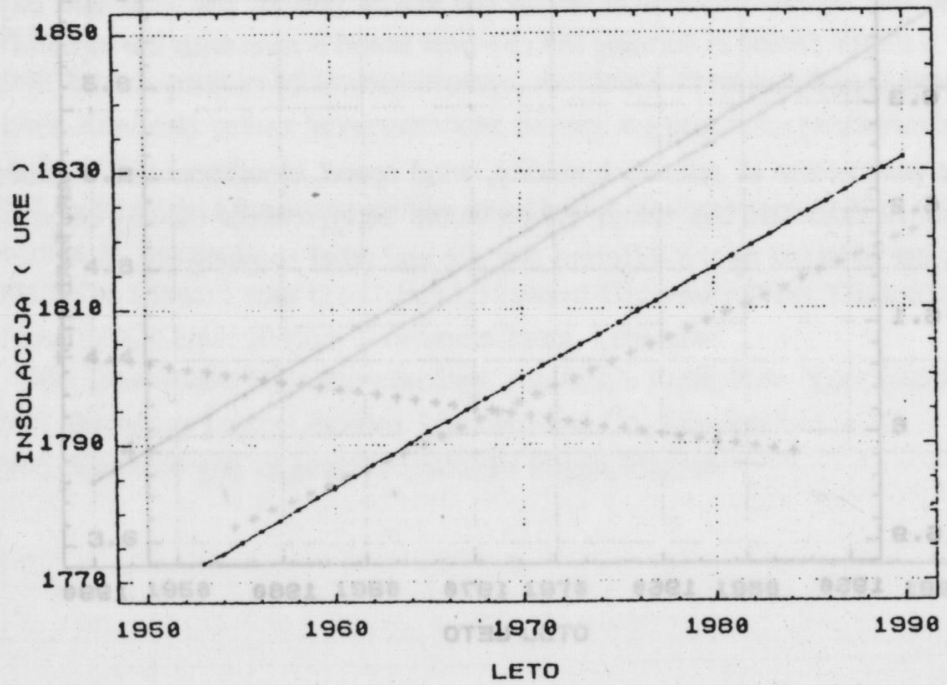




\section{Tabela 1}

Sezonske vrednosti izbranih klimatskih parametrov za meteoroloski postaji Maribor-Tabor in Maribor-ketališ̌ce v obdobju 1977 - 1990

MARIBOR-TABOR

\begin{tabular}{|c|c|c|c|c|c|c|c|c|}
\hline parameter & telenoy & ancix & clat & leto & zima & pomlad & poletje & jesen \\
\hline \multicolumn{2}{|c|}{ povpr. temp. zraka ob 7. uri $\left({ }^{\circ} \mathrm{C}\right)$} & $\overline{c a n}$ & $\bar{x}$ & 7,1 & $-1,7$ & 6,9 & 16,2 & 7,1 \\
\hline \multicolumn{2}{|c|}{ povpr. temp. zraka ob 14 . uri $\left({ }^{\circ} \mathrm{C}\right)$} & 7.5 & e. 24 & 13,7 & 3,2 & 14,1 & 23,2 & 14,4 \\
\hline \multicolumn{2}{|c|}{ povpr. temp. zraka ob 21 . uri $\left({ }^{\circ} \mathrm{C}\right)$} & $8,0=$ & 2.8 & 9,2 & $-0,2$ & 9,5 & 18,1 & 9,3 \\
\hline \multicolumn{2}{|l|}{ povpr. temp. zraka $\left({ }^{\circ} \mathrm{C}\right)$} & $3: 0=$ & $c_{1} e^{2}$ & 9,8 & 0,3 & 10,0 & 18,9 & 10,0 \\
\hline \multicolumn{2}{|c|}{ povpr. maksim. temp. $\left({ }^{\circ} \mathrm{C}\right)$} & P.8 & 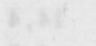 & 14,8 & 4,2 & 15,3 & 24,5 & 15,2 \\
\hline \multicolumn{2}{|l|}{ povpr. minim. temp. $\left({ }^{\circ} \mathrm{C}\right)$} & $2+15=$ & 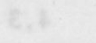 & 5,5 & $-3,0$ & 5,2 & 13,9 & 6,0 \\
\hline \multicolumn{2}{|l|}{ absolutna maksim. temp. $\left({ }^{\circ} \mathrm{C}\right)$} & $5,+1$ & 8,26 & 26,6 & 19,1 & 27,1 & 34,0 & 26,3 \\
\hline \multicolumn{2}{|c|}{ absolutna minim. temp. $\left({ }^{\circ} \mathrm{C}\right)$} & 8.35 & 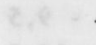 & $-6,6$ & $-19,6$ & $-6,5$ & 5,2 & $\cdot 5,6$ \\
\hline \multicolumn{2}{|c|}{ st. dni $\mathrm{z}$ minim. temp. $<=-10,0^{\circ} \mathrm{C}$} & $1,2,1$ & $2 .+36$ & 7,4 & 6,7 & 0,4 & 0,0 & 0,3 \\
\hline \multicolumn{2}{|c|}{ st. dni $\mathrm{z}$ maksim. temp. $<0,0^{\circ} \mathrm{C}$} & 4. is & 4hes & 10,3 & 10,2 & 0,1 & 0,0 & 0,1 \\
\hline \multicolumn{2}{|c|}{ št. dni $\mathrm{z}$ minim. temp. $<0,0^{\circ} \mathrm{C}$} & 3.45 & 0,211 & 32,2 & 29,7 & 1,1 & 0,0 & 1,4 \\
\hline povpr. relativna vlaga (\%) & 0.87 & T. Ele & S., 87 & 74,4 & 79,3 & 68,5 & 70,7 & 79,1 \\
\hline povpr. oblažnost ( $v$ deset.) & 8,25 & 230 & 8,28 & 6,1 & 6,8 & 6,4 & 5,4 & 5,8 \\
\hline Stevilo jasnih dni & E, 114 & 8,05 & 1,52 & 48,5 & 9,8 & 10,1 & 14,0 & 14,6 \\
\hline Stevilo oblažnih dni & 1.28 & $5, \sqrt{58}$ & 12 & 121,6 & 40,8 & 32,9 & 18,9 & 29,0 \\
\hline kolixina padavin (mm) & $2, \operatorname{sos}$ & 5,121 & 1 & 1032,1 & 176,1 & 231,0 & 358,0 & 266,9 \\
\hline število dni z meglo & c,, 1 & 2,05 & 20.04 & 26,6 & 11,2 & 2,2 & 0,8 & 12,4 \\
\hline pogostost calm (\%) & $9, k 5$ & 3,28 & 2,18 & 2,2 & 2,6 & 1,5 & 1,7 & 2,8 \\
\hline st. dni $\mathrm{z}$ vetrom $>=6 \mathrm{Bf}$ & e.5S & $e, E 1$ & 8.92 & 18,5 & 3,5 & 7,8 & 4,2 & 2,9 \\
\hline st. dni $\mathrm{z}$ vetrom $>=8 \mathrm{Bf}$ & 8.0 & 20.0 & a & 1,2 & 0,2 & 0,2 & 0,6 & 0,1 \\
\hline povpr. jakost vetra (Bf) & 0,5 & 8.1 & 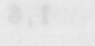 & 2,2 & 2,0 & 2,4 & 2,2 & 2,0 \\
\hline povpr. jakost vetra iz smeri & $\mathrm{N}(\mathrm{Bf})$ & 5.5 & 9.8 & 2,1 & 2,2 & 2,4 & 2,1 & 1,9 \\
\hline povpr. jakost vetra iz smeri & $\mathrm{NE}(\mathrm{Bf})$ & 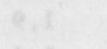 & 8,1 & 2,1 & 1,9 & 2,4 & 2,2 & 1,9 \\
\hline povpr. jakost vetra iz smeri & $\mathrm{E}(\mathrm{Bf})$ & 1.1.1 & 2,7 & 1,7 & 1,6 & 1,9 & 1,9 & 1,6 \\
\hline povpr. jakost vetra iz smeri & $\mathrm{SE}(\mathrm{Bf})$ & 8,1 & anis & 2,3 & 2,1 & 2,5 & 2,4 & 2,2 \\
\hline povpr. jakost vetra iz smeri & $\mathrm{S}(\mathrm{Bf})$ & 4,5 & $6, x^{2}$ & 2,7 & 2,5 & 3,1 & 2,8 & 2,5 \\
\hline povpr. jakost vetra iz smeri & $\mathrm{SW}(\mathrm{Bf})$ & 8,5 & 0,6 & 2,1 & 1,9 & 2,5 & 2,2 & 1,9 \\
\hline povpr. jakost vetra iz smeri & $\mathrm{W}(\mathrm{Bf})$ & S., & e. 1 & 2,1 & 2,1 & 2,4 & 2,2 & 2,0 \\
\hline povpr. jakost vetra iz smeri & $\mathrm{NW}(\mathrm{Bf})$ & 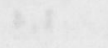 & 2.18 & 2,2 & 2,2 & 2,3 & 2,2 & 2,0 \\
\hline
\end{tabular}




\section{Tabela 1 (nadaljevanje)}

\section{MARIBOR-LETALIŠČE}

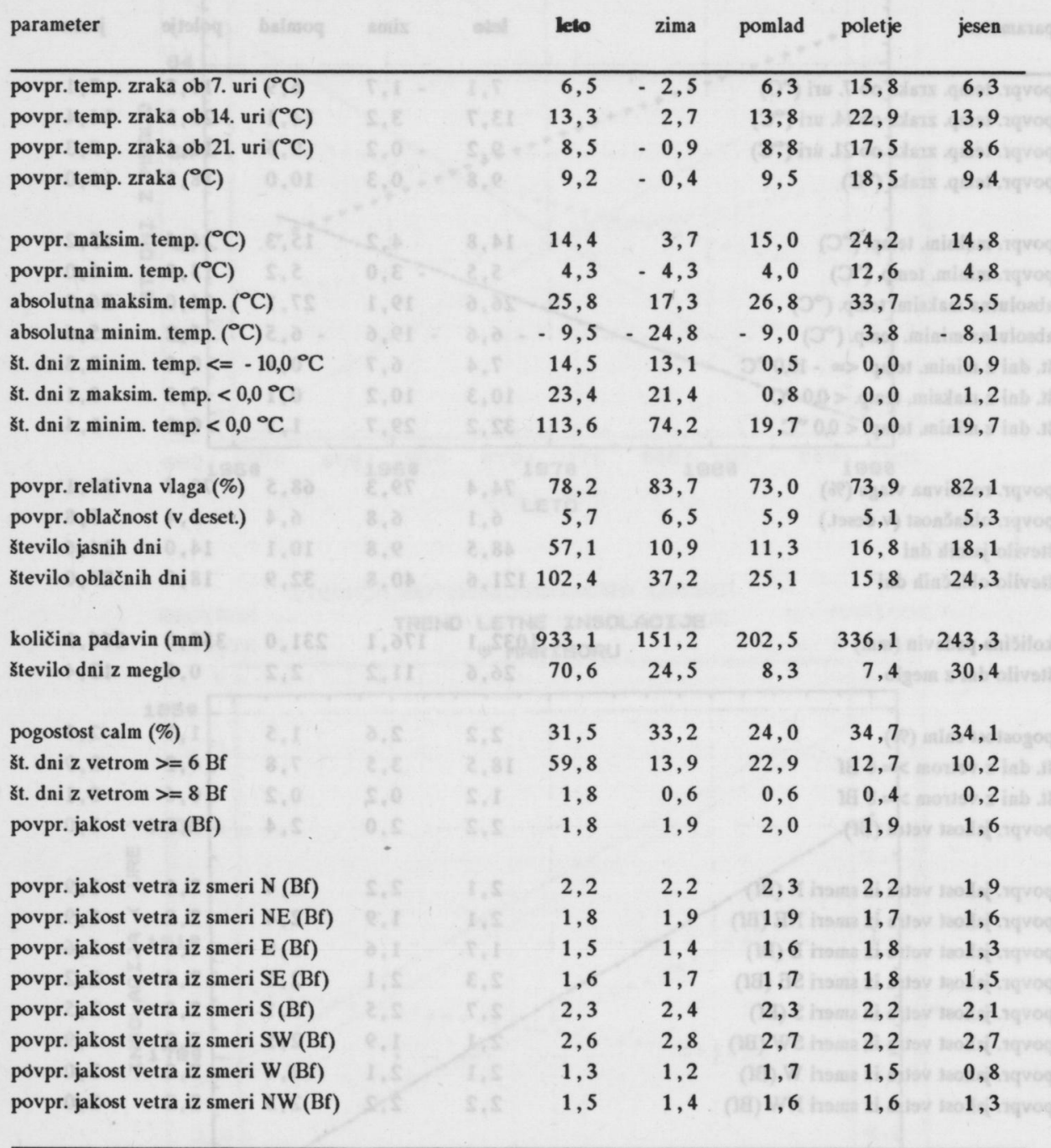

Vir: Arhiv HMZ RS 
Tabela 2

Razlike v vrednostih klimatskih parametrov (Maribor-Tabor - Maribor-letališce) v obdobju 1977 - 1990

parameter

leto zima pomlad poletje jesen

povpr. temp. zraka ob 7 . uri $\left({ }^{\circ} \mathrm{C}\right)$

povpr. temp. zraka ob 14 . uri $\left({ }^{\circ} \mathrm{C}\right)$

povpr. temp. zraka ob 21 . uri $\left({ }^{\circ} \mathrm{C}\right)$

povpr. temp. zraka $\left({ }^{\circ} \mathrm{C}\right)$

povpr. maksim. temp. $\left({ }^{\circ} \mathrm{C}\right)$

povpr. minim. temp. $\left({ }^{\circ} \mathrm{C}\right)$

absolutna maksim. temp. $\left({ }^{\circ} \mathrm{C}\right)$

absolutna minim. temp. $\left({ }^{\circ} \mathrm{C}\right)$

st. dni $\mathrm{z}$ minim. temp. $<=-10,0^{\circ} \mathrm{C}$

st. dni $\mathrm{z}$ maksim. temp. $<0,0^{\circ} \mathrm{C}$

st. dni $\mathrm{z}$ minim. temp. $<0,0^{\circ} \mathrm{C}$

povpr. relativna vlaga (\%)

povpr. oblačnost (v deset.)

število jasnih dni

število oblačnih dni

kolixina padavin (mm)

stevilo dni z meglo

pogostost calm (\%)

st. dni $\mathrm{z}$ vetrom $>=6 \mathrm{Bf}$

št. dni $\mathrm{z}$ vetrom $>=8 \mathrm{Bf}$

povpr. jakost vetra (Bf)

povpr. jakost vetra iz smeri $\mathrm{N}$ (Bf) povpr. jakost vetra iz smeri NE (Bf) povpr. jakost vetra iz smeri $\mathrm{E}$ (Bf) povpr. jakost vetra iz smeri SE (Bf) povpr. jakost vetra iz smeri $S$ (Bf) povpr. jakost vetra iz smeri SW (Bf) povpr. jakost vetra iz smeri W (Bf) povpr. jakost vetra iz smeri NW (Bf)

$\begin{array}{lllll}0,7 & 0,8 & 0,6 & 0,4 & 0,9 \\ 0,4 & 0,6 & 0,3 & 0,3 & 0,4 \\ 0,6 & 0,7 & 0,7 & 0,6 & 0,6 \\ 0,6 & 0,7 & 0,6 & 0,5 & 0,6\end{array}$

$\begin{array}{lllll}0,4 & 0,5 & 0,4 & 0,3 & 0,4\end{array}$

$\begin{array}{lllll}1,2 & 1,3 & 1,2 & 1,3 & 1,2\end{array}$

$\begin{array}{lllll}0,8 & 1,8 & 0,3 & 0,3 & 0,8\end{array}$

$\begin{array}{rrrrr}2,9 & 5,2 & 2,6 & 1,5 & 2,5\end{array}$

$\begin{array}{lllll}-7,2 & -6,4 & -0,2 & 0,0 & -0,6\end{array}$

$\begin{array}{lllll}-13,1-11,2 & -0,7 & 0,0 & -1,2\end{array}$

$-81,5-44,6-18,6 \quad 0,0-18,3$

$\begin{array}{lllll}-3,8 & -4,4 & -4,5 & -3,3 & -3,0\end{array}$

$\begin{array}{lllll}0,4 & 0,3 & 0,6 & 0,4 & 0,4\end{array}$

$\begin{array}{lllll}-8,7 & -1,2 & -1,2 & -2,8 & -3,5\end{array}$

$\begin{array}{lllll}19,2 & 3,5 & 7,8 & 3,2 & 4,7\end{array}$

$\begin{array}{lllll}98,9 & 24,9 & 28,5 & 21,9 & 23,6\end{array}$

$44,0-13,4-6,1-6,5-18,0$

$-29,3-30,5-22,4-33,0-31,3$

$-41,3-10,4-15,1-8,5-7,3$

$\begin{array}{lllll}-0,8 & -0,4 & -0,4 & 0,2 & -0,2\end{array}$

$\begin{array}{lllll}0,3 & 0,2 & 0,4 & 0,4 & 0,4\end{array}$

$\begin{array}{rrrrr}0,0 & -0,1 & 0,1 & -0,2 & 0,0 \\ 0,3 & 0,0 & 0,5 & 0,5 & 0,3 \\ 0,2 & 0,2 & 0,2 & 0,1 & 0,3 \\ 0,7 & 0,4 & 0,8 & 0,6 & 0,7 \\ 0,4 & 0,0 & 0,7 & 0,6 & 0,4 \\ 0,5 & -1,0 & -0,2 & 0,0 & -0,7 \\ 0,9 & 0,9 & 0,7 & 0,7 & 1,2 \\ 0,7 & 0,8 & 0,7 & 0,6 & 0,8\end{array}$

Vir: Arhiv HMZ RS 


\section{Tabela 3}

\section{Trendi izbranih klimatskih parametrov v Mariboru in Starsah v obdobju 1953 - 1990}

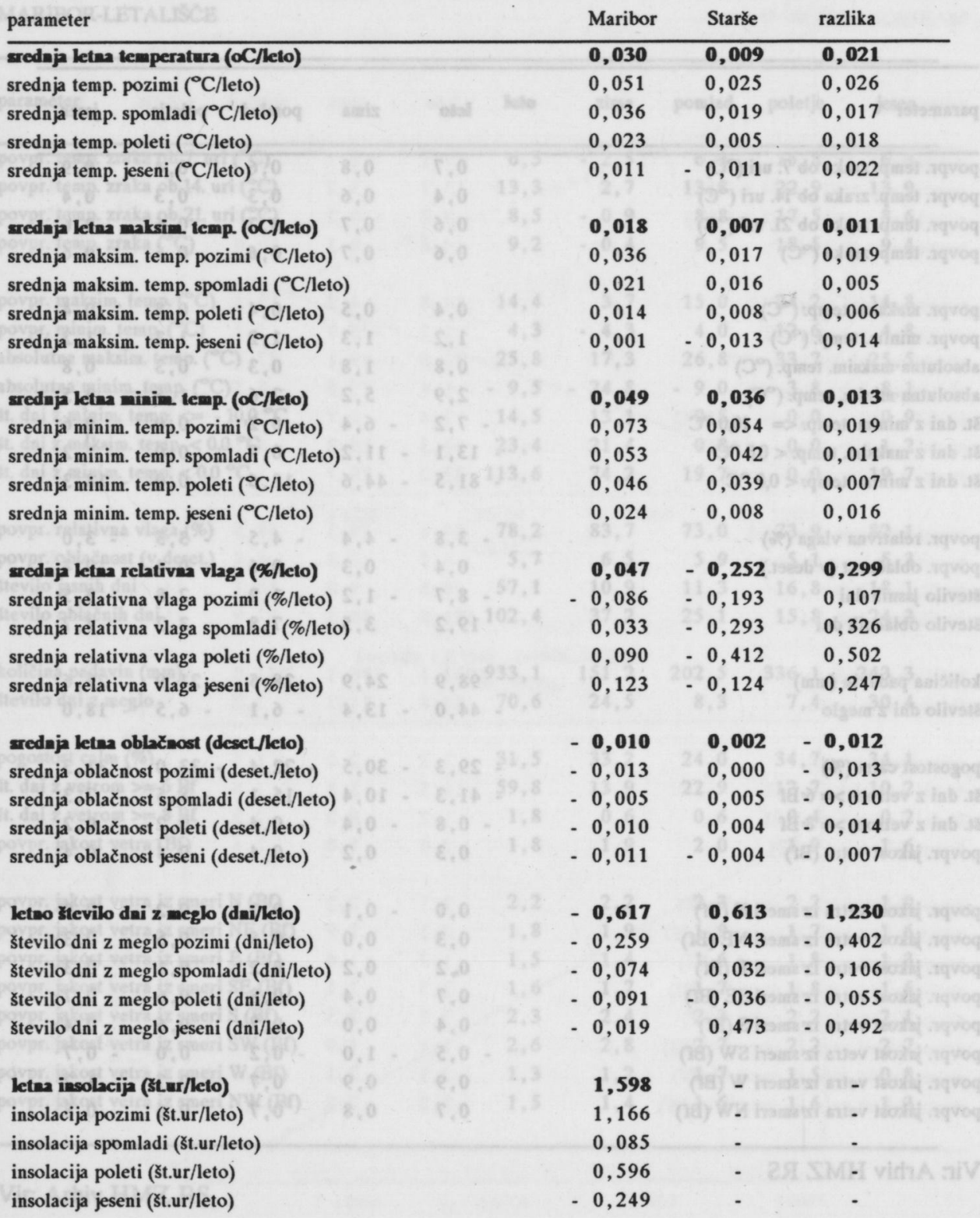

